\title{
Giant Parathyroid Adenoma
}

\author{
Jayant $\mathrm{M},{ }^{1}$ Kaushik $\mathrm{R},{ }^{1}$ Kochar $\mathrm{S},{ }^{2}$ Attri A K ${ }^{1}$
}

${ }^{1}$ Department of General Surgery, ${ }^{2}$ Department of Radiodiagnosis

Government Medical College \& Hospital

Sector -32, Chandigarh - India

Corresponding Author

Dr Mayank Jayant

H No 1208 , Sector 32 B,Chandigarh (India)

Email: mayankjayant@rediffmail.com

\section{Citation}

Jayant M, Kaushik R, Kochar S, Attri A K. Giant Parathyroid Adenoma. Kathmandu Univ Med J 2011;33(1)77-9.

\begin{abstract}
Primary Hyperparathyroidism is most commonly caused by parathyroid adenoma. Parathyroid adenoma is generally suspected by certain symptoms and biochemical abnormalities. They rarely attain large size to be evident clinically. We report a rare case of giant parathyroid adenoma measuring $5 \times 4 \times 3 \mathrm{~cm}$ and weighing $35 \mathrm{gm}$.
\end{abstract}

\section{KEY WORDS}

hyperparathyroidism, parathyroid adenoma

\section{INTRODUCTION}

Primary hyperparathyroidism is not a rare disease and is generally caused by either adenoma or hyperplasia of the parathyroid gland. Solitary parathyroid adenomas account for $80 \%$ of the cases of primary hyperarathyroidism. ${ }^{1}$ Parathyroid adenomas generally remain small in size and usually weigh around $70 \mathrm{mg}$ to one gm. ${ }^{2,3}$ Hyperparathyroidism due to parathyroid adenoma is suspected on the basis of clinical features like vague abdominal pain, neuromuscular weakness, bone disease or recurrent nephrolithiasis and diagnosed by deranged biochemical parameters of hypercalcemia and raised Parathyroid hormone (PTH) levels. ${ }^{3-5}$ These benign tumours are localised by non invasive modalities using ultrasonography of the neck and parathyroid scintigraphy. ${ }^{4,5}$ Parathyroid adenomas very rarely attain large sizes and adenomas more than two grams are termed 'Giant Parathyroid Adenoma'. ${ }^{6}$ Very few adenomas weighing more than 30 gms have been described in literature and we present one such case.

\section{CASE REPORT}

A 45 year old female with fracture of the right femur was referred to surgical OPD for examination of a neck swelling discovered on her routine physical examination. She had history of vague abdominal pain for last two years and the presence of painless lump on the right side of her neck for last six months. The lump was present in right lower neck and measured approximately $4 \times 3 \mathrm{~cm}$. It was discrete, firm and moved on swallowing. Ultrasonography showed a relatively hypoechoic lesion of approximately $4 \times 3 \times 3 \mathrm{~cm}$ in right lower parathyroid with areas of haemorrhage and necrosis. Thyroid functions were normal, but there was marked elevation of serum $\mathrm{Ca}^{++}$levels $(14.2 \mathrm{mg} / \mathrm{ml})$. With clinical picture and raised calcium levels, hyperparathyroidism was suspected and serum parathyroid hormone was measured, which was markedly raised i.e $1,543 \mathrm{pg} / \mathrm{ml}$. The patient was subjected to Tc 99- Sestamibi scan which showed hyper functioning right lower parathyroid gland (Fig 1). Right lower parathyroid gland was excised which measured five by four by three centimetres and weighed approximately 35 gms 
(Fig 2). Histopathology of the specimen was consistent with parathyroid adenoma. The parathyroid hormone levels fell to normal limits approximately 12 hours after surgery.

\section{DISCUSSION}

Solitary parathyroid adenomas account for approximately

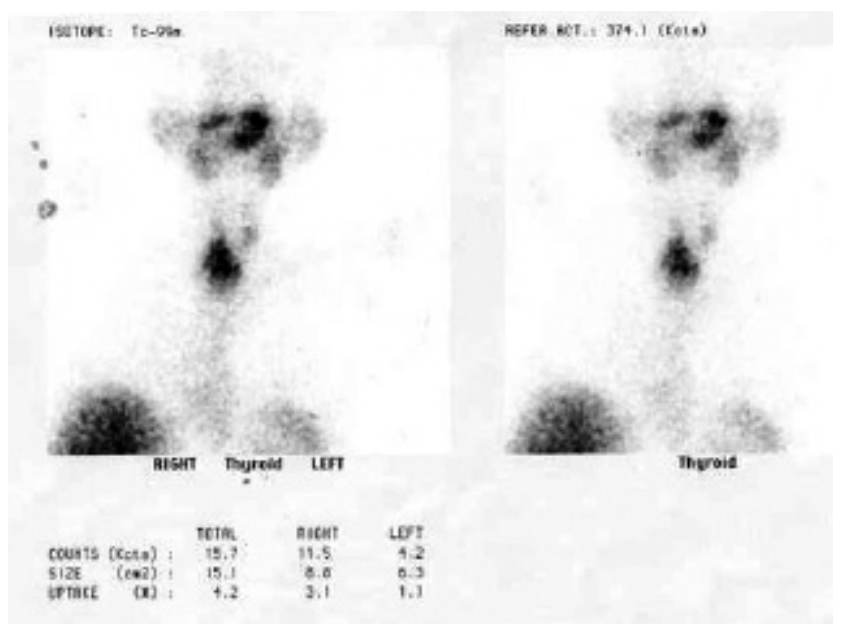

Figure 1. Tc 99- Sestamibi scan which showed hyper functioning right lower parathyroid gland

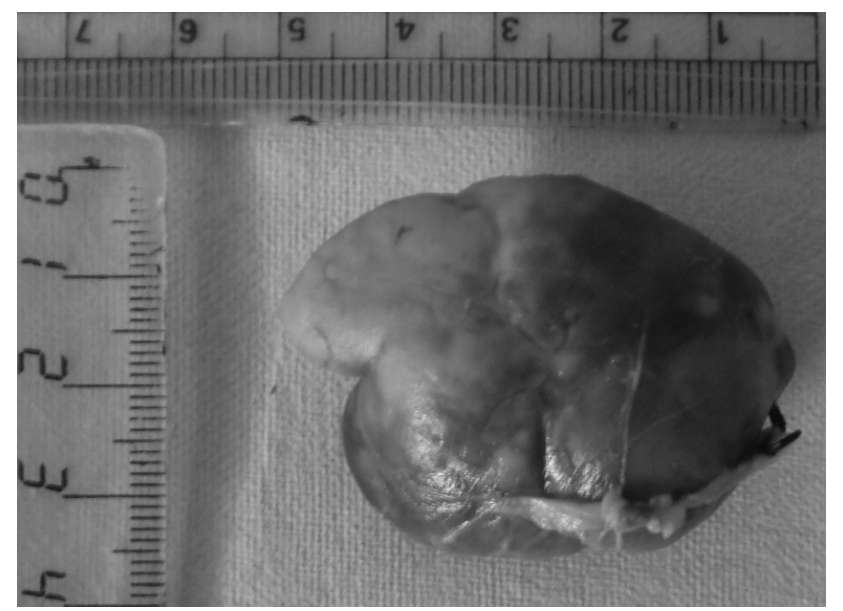

Figure 2. Photograph showing Parathyroid Adenoma a measuring

\section{$5 \times 4 \times 3 \mathrm{cms}$}

$80 \%$ of all the cases of Primary hyperparathyroidism and rarely multiple adenoma, hyperplasia and carcinoma (1-2\%) cause the same. ${ }^{1,5}$ The basic pathophysiological abnormality in primary hyperparathyroidism is the increased secretion of parathyroid hormone, which promotes the absorption of calcium from bones by stimulating osteoclasts and inhibiting osteoblasts. In the kidney, parathyroid hormone decreases the calcium clearance and increases the renal excretion of phosphate. Parathyroid hormone also stimulates the hydroxylation of 25 hydroxy Vit D to 1,25 dihydroxy Vit D which enhances the calcium absorption in intestines. ${ }^{7}$ Due to multi-systemic effects of parathyroid hormone, patients with hyperparathyroidism can present with a variety of symptoms in varying proportions: nephrolithiasis (30\%), bone diseases (2\%), peptic ulcer disease $(12 \%)$, psychiatric disorders (15\%), muscle weakness (70\%), constipation $(32 \%)$, polyuria $(28 \%)$, pancreatitis $(1 \%)$, myalgia $(54 \%)$ and arthralgia (54\%). ${ }^{2}$ The diagnosis is confirmed by typical biochemical picture showing raised serum calcium and parathyroid hormone concentration. ${ }^{3}$ Cervical ultrasonography and parathyroid Scintigraphy are used for exact localization of hyper functioning parathyroid gland. ${ }^{3}$

Parathyroid adenomas rarely attain large sizes to become clinically evident. Normally the parathyroid adenomas weigh around 0.4 to $1.2 \mathrm{gm} .{ }^{8}$ Adenomas more than $2 \mathrm{gm}$ are termed as 'Giant Parathyroid Adenoma'. ${ }^{6}$ There are very few descriptions of giant parathyroid adenoma weighing more than 30 gms. Only 16 cases of parathyroid adenoma more than 30 gms have been reported. ${ }^{3}$ The largest parathyroid adenoma was $8 \times 5 \times 3.5 \mathrm{~cm}$ and weighed $110 \mathrm{gm}^{2}$ Other giant parathyroid adenoma reported included a $70 \mathrm{gm}$ adenoma measuring $6 \times 4 \times 3.5 \mathrm{~cm}$ by Tsuchiya et al and a 75 gm adenoma $(6 \times 5 \times 5 \mathrm{~cm})$ reported by Masako et al. ${ }^{4,9}$ The parathyroid adenoma in our patient measured $5 \times 4 \times 3 \mathrm{~cm}$ and weighed $35 \mathrm{gm}$, also deserves documentation.

There is enough evidence that the adenoma weight has direct correlation with the functional status of the gland. ${ }^{10}$ Many studies have established the direct relationship between gland weight and serum calcium and parathyroid hormone levels. ${ }^{11,12}$ In our patient also this relationship was true. But a very interesting case of giant non parathyroid hormone producing adenoma measuring $7 \times 6 \times 5 \mathrm{~cm}$ has also been described. ${ }^{13}$

Surgical excision is the treatment of choice for these benign tumours. Technetium -99 Sestamibi scan is the diagnostic modality most commonly employed to locate the culprit parathyroid gland and plan the surgery accordingly. Minimally invasive parathyroidectomy has also been described for giant parathyroid adenoma with similar safety and efficacy as for smaller adenomas. ${ }^{6}$ Due to short half life of parathyroid hormone and calcium deplete bones, the patient can land into severe hypocalcaemia in immediate post operative period. So, strict monitoring of serum calcium levels should be done and appropriate calcium supplementation should be given.

We conclude that giant parathyroid adenoma causing primary hyperparathyroidism should also be kept in mind in patients presenting as neck lump with recurrent bone disease or renal stones. Raised calcium and parathyroid hormone levels clinch the diagnosis. 


\section{REFERENCES}

1. John T, Potts Jr. Disease of the parathyroid gland and other hyper and hypo calcemic disorders. In : Fauci AS, Braunwald E, Isselbacher $\mathrm{KJ}$, Wilson JD, Martin JB, Kasper DL,editors.Harrison's principles of internal medicine. $16^{\text {th }}$ ed.New York :McGraw -Hill Co ; 2005:2249-67.

2. Power D, Kavanagh D, Hill ADK, O'Higgins N, Mcdermott E.Unusual presentation of a Giant Parathyroid Adenoma :Report of a Case. Surg Today 2005;35:235-237.

3. Salehian MT, Namdari O, Mohammadi SS, Fazaeli Yousofabad H.Primary Hyperparathtyroidism due to a Giant Parathyroid Adenoma : A case report.Int J Endocrinol Metab 2009;2:101-105.

4. Tsuchiya A,Seiji E,Abe R. Giant Adenoma of the Parathyroid :Report of a case. Surg Today 1993;23;465-467.

5. Sai Prasad TR,Bhatnagar V.Giant Solitary Parathyroid Adenoma Presenting with bone disease.Indian Pediatrics 2002 ;39:1044-1047.

6. Meyer-Rochow GY,Sidhu SB, Delbridge LW, Grodski S,Sywak MS.Can Giant Parathyroid Adenomas be safely removed by minimally invasive Parathyroidectomy. ANZ Journal of Surgery 2007;77:A23-A23(1).

7. Gauger PG,Doherty GM. Paratjyroid Gland . In :Townsend CM, Evers BM,Beauchamp RD,Mattox KL editors .Sabiston Textbook of Surgery. $17^{\text {th }}$ ed .Philadelphia : Saunders / Elsevier $2004 ; 1063-1078$.

8. Rosai J.Parathyroid Gland. In : Rosai J editors . Ackerman's Surgical Pathology . 6 th $^{\text {th }}$. St. Louis : CV Mosby 1981 ;p379-399.

9. Masako I, Tetsuaki K, Kazuo M, Hideki T, Hajime H, Satoshi N.A case of Giant Parathyroid Adenoma. Practica Otologica 2002 ; 109:119-123.

10. Zamboni WA ,Folse R.Adenoma weight : a predictor of transient hypocalcemia after parathyroidectomy.Am J Surg 1986; 152:611-615.

11. Rao DS, Honasoge M, Divine GW, Phillips ER, Lee MW, Ansari MR etal. Effect of vitamin $D$ nutrition on parathyroid adenoma weight : pathogenetic and clinical implications .J Clin Endocrinol Metab 2000;85:1054-63.

12. Mozes G, Curlee KJ, Rowland CM, Van Heerden JA, Thompson Gb, Grant CS.The predictive value of laboratory findings in patients with primary hyperparathyroidism.J Am Coll Surg 2002;194:126-130.

13. Kiverniti E ,Kazi R, Rhys-Evans P,Nippah R.Airway obstruction due to gaint non-parathyroid hormone producing parathyroid adenoma. J Cancer Res Ther 2008;4:197-9. 